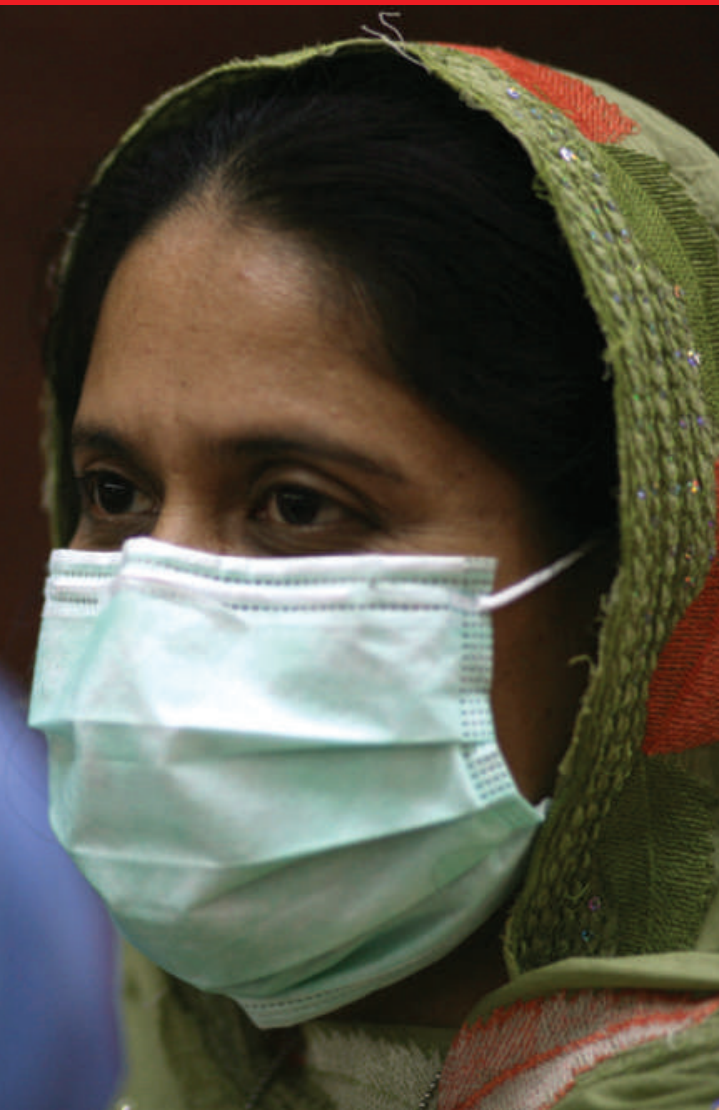

The logical conclusion, he says, is that although surveillance is needed in temperate countries in the Southern Hemisphere during the upcoming flu season, deep sampling of tropical regions would be even more helpful. "But unsurprisingly, surveillance has historically been best in rich countries" that tend to be in temperate latitudes, he says.

On 22 May, Margaret Chan, director-general of the WHO, told the annual meeting of the World Health Assembly - the agency's supreme decision-making body - that nations must unite to help poor countries in the Southern Hemisphere implement control measures. "I strongly urge you to look closely at anything and everything we can do, collectively," she said, " to protect developing countries from, once again, bearing the brunt of a global contagion."

Declan Butler

1. Rambaut, A. et al. Nature $453,615-619$ (2008).

2. Russel, C. A. et al. Science 320, 340-346 (2008).

For Nature's swine flu coverage,

see nature.com/swineflu

\section{HiN1 update}

As confirmed by the World Health

Organization, as of 26 May:

Cases: 12,954, in 46 countries

Deaths: 92 , in 4 countries

AUSTRALIA: Raised the pandemic level to

'Contain' on 22 May, giving authorities the power to close schools.

JAPAN: Urged people not to panic as case numbers reached 350 and spread to Tokyo.

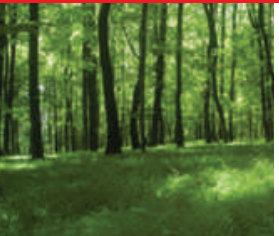

FORESTS AT RISK

International preservation targets will not be met by 2010 .

www.nature.com/news

\title{
North Korea's bigger blast
}

On the morning of 25 May, when North Korea announced that it had tested a second nuclear device, supporting evidence was already available in the form of waves picked up by seismic stations around the world within minutes. But piecing together what the blast means in terms of the nation's nuclear capacity will take a lot longer.

At 09:55 local time on 25 May, monitors in the Shimane and Tottori prefectures on the Japanese coast picked up seismic waves emanating from the region where North Korea tested a nuclear weapon in 2006 an area with little natural seismic activity. Movements along natural fault lines transmit most of their energy through 's-waves', whereas explosions at a single point release a greater proportion through compressional p-waves. In the waves detected in Japan, the s-wave component was just one-fifth that of the p-wave. "You can't say it's impossible for a natural earthquake, but it would be very rare," says Gen Aoki of the Japan Meteorological Agency in Tokyo.

Japanese officials determined the tremors to be of magnitude 5.3. The US Geological Survey put the strength at 4.7, and the Comprehensive Test Ban Treaty Organization (CTBTO) recorded a magnitude of around 4.5. All three estimates are consistent with a blast equivalent to a few thousand tonnes of TNT.

The yield of North Korea's 2006 test was estimated to be under a kilotonne, and most experts think that it was a 'fizzle' - a detonation in which the nuclear device fails to create a complete chain reaction in its fuel. North Korea's weapons programme uses plutonium, which needs to be compressed with carefully synchronized explosive charges to detonate properly.

Linking the magnitude readings to the explosive power depends on knowledge of the surrounding earth, but the latest test seems to have been around five times the size of the 2006 test, according to Paul Richards, a seismologist at Columbia University in New York. Richards says that the blast was too large to have come from conventional explosives. "To me, a chemical explosion on the order of a few thousand tonnes, with all the stuff detonated at all the same instant, is not a credible scenario," he says.
Martin Kalinowski, a nuclear physicist at the University of Hamburg in Germany, agrees, but says that the test may not have been a complete success. He was expecting a yield of roughly 16 kilotonnes, in line with the first nuclear tests of other nations. Assuming that was the case, then Monday's test "was probably not the yield that North Korea expected", he says.

Others, however, think that North Korea wanted a small blast. In 2006, the nation told the Chinese that its bomb would have a yield of around 4 kilotonnes, according to Andreas Persbo, a senior researcher at

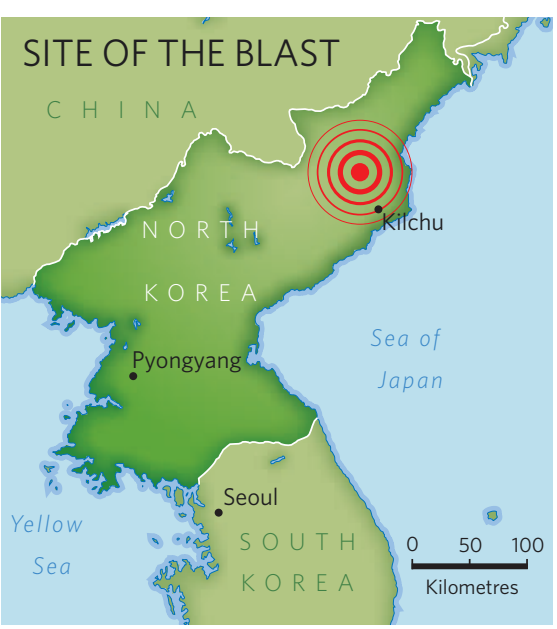

the Verification Research Training and Information Centre (VERTIC) in London. Given the limited amount of nuclear material available to the North Koreans, a small yield might be a sensible choice. "It certainly looks successful to me," he says.

Further confirmation of the nuclear nature of the test is likely to come in the next few weeks. If the underground blast was indeed nuclear, then it will have released radioactive xenon isotopes in ratios that are distinct from those released by other sources, such as nuclear power stations. A representative at Japan's Ministry of Foreign Affairs says that its two radionuclide monitoring stations will not have any results for a couple of days; ground-based CTBTO testing stations in Russia could see the first xenon within the next few days, although it will take weeks to complete the measurements, Kalinowski says. Specially equipped US military aircraft are also likely to be used in the follow up.

Geoff Brumfiel and David Cyranoski 